\title{
The botanist; containing accurately coloured figures of tender and hardy ornamental plants, with descriptions
}

\section{B. Maund F.L.S.}

To cite this article: B. Maund F.L.S. (1836) The botanist; containing accurately coloured figures of tender and hardy ornamental plants, with descriptions, Philosophical Magazine Series 3, 9:55, 371-372, DOI: $10.1080 / 14786443608649018$

To link to this article: http://dx.doi.org/10.1080/14786443608649018

曲 Published online: 01 Jun 2009.

Submit your article to this journal $[\pi$

Џll Article views: 2

Q View related articles $₫$ 
or, which is the same thing,

$$
\mathrm{R}=p \frac{r^{3}}{\mathrm{P}^{3}}, \ldots \ldots \ldots
$$

as the general equation of the conic sections.

For since the force in the radius vector varies as $\frac{1}{r^{3}}$, its component in the direction of the normal must vary as $\frac{1}{r^{2}} \cdot \frac{\mathrm{P}}{r}$. But the normal force is

and consequently

$$
\frac{v^{2}}{\mathrm{R}}=\frac{\mathrm{C}}{\mathrm{P}^{3} \mathrm{R}} \therefore \frac{\mathrm{P}^{3}}{r^{3}} \mathbf{R}=\mathrm{C}^{\prime} ;
$$

$$
\mathbf{R}=\mathbf{C}^{\prime} \frac{r^{3}}{\mathrm{P}^{3}}, \ldots \ldots
$$

which equation, as it agrees with (3.), represents a conic section, whose parameter, $2 \mathrm{C}^{\prime}$, is determinable from the initial circumstances of the motion.

LXXIII. Revieres, and Notices respecting Nero Books.

The Botanist; containing accurately Coloured Figures of tender and hardy Ornamental Plants, with Descriptions. Conducted by $\mathbf{B}$. Maund, F.LS., assisted by Professor Henslow. 4to. To be continued Monthly. No. I.

T $N$ the progress of science there occur periods when the establish. 1 ment of works devoted to any of its branches, upon new plans, becomes absolutely necessary, in order to promote its advancement, by being conformable to the improvements already achieved. Former works cannot so easily be moulded to the changing conditions of modern science as new ones can be accommodated to its state at the time of commencing their career. Hence, in the science to which the work refers, of which we have above transcribed the title, every succeeding work undertaken by competent persons has been an improvement upon its precursors. Most of those in existence up to this time have been suited or addressed to those only who were already conversant with its language and classification. But an attempt is here made to render an illustrated work suitable to those who have mastered its elements, and conducive to the acquisition of these by beginners. The terms used in the descriptions of plants are in general unintelligible to the uninitiated, and therefore fittle more is learnt by reading the description than by looking at the plate. But in the work just started an explanation of every botanical term is given, by means of a glossary, from the pen of Professor Henslow, a portion of which, till it be completed, will accompany each number, and to which reference can be made in every case of 
doubt. This is an advantage which belongs to no previous work, and must greatly enhance the usefulness of The Botanist. The plates, both in the matter of engraving and colouring, speak for themselves : they are " beautiful exceedingly!" The selection and treatment of the subjects figured reflect credit upon the conductor and his assis. tants, and if they avail themselves in the future numbers as judiciously of the varied resources at their command, the result will be the pr o duction of a volume, or, as we hope, many volumes, calculated to delight and instruct all who may open them, of whatever age or sex.

M. Mirbel's Report on a Memoir of M. Gaudichaud, relative to the Development and Growth of the Stems, Leaves, and other Organs of Plants, read in the Academy of Sciences at the sitting of the 21 st December 1835.*

When we have collected a great number of facts, when we have viewed them on every side, and have compared them with one another, observing with care their resemblances and differences, we feel ourselves stimulated by the desire to seek out the laws of their existence, to generalize those which are susceptible of it, and to form them into a theory. Without doubt prudence would often lead us to keep to the simple exposition of facts, but we cannot deny that it is very useful for science, that those who have discovered them should apply themselves to show us their connexion and dependence. Exact observations are never slow in obtaining the assent of all; theories, on the contrary, are subject to be for a long time contested. In this conflict of different opinions, the opposing parties bring forward all the known facts, put them to the test of a more rigorous examination, and discover others which had escaped preceding researches. Now, numerous and well-observed facts are what essentially constitute the unchangeable foundations of science. Thus, whatever be the issue of the struggle, there is a victory in favour of the human mind, and both the victors and the vanquished have often equal claims to public esteem.

These reflections are suggested to us by the perusal of the work which M.Gaudichaud has addressed to the Academy,-a work which, on the one part, is composed of a multitude of new facts, of acute observations, and inductions as just as they are evident; and, on the other, presents a general theory which rests upon that of Du PetitThouars, and considerably enlarges its basis. 'The material facts are certain, the theory which generalizes and professes to explain them, is still in doubt. De la Hire conceived it without supporting it by proofs : Du Petit-Thouars, by bringing together all the observations that seemed to him calculated to support it, gave it a scientific existence; Agardh applied himself to reconcile it with the re-

* From the Annales des Sciences Naturelles, tome v. p. 24.-The prize for experimental physiology founded by $M$. Montyon for the year 1835 was divided between this memoir and that of $M$. Poiseuille upon the causes of the motion of the blood in the capillary vessels. 